\title{
UPGRADE OF CORROSIVENESS NATURE OF FISH WASTE BIO-OIL USING A HYBRID CATALYST (MGO/NA2CO3) OPTIMIZATION PROCESS
}

\author{
1,3 Nadia MRAD \\ ${ }^{1}$ Laboratoire M2P2, UMR-CNRS 6181, Universités \\ d'Aix-Marseille, École Centrale Marseille \\ Technopôle Château Gombert 38 rue Joliot Curie, \\ 13451 Marseille cedex 20, France \\ E-mail: nadia.mrad@gmail.com
}

\author{
${ }^{2 *}$ Fethi ALOUI \\ ${ }^{2}$ Université de Valenciennes et du \\ Hainaut-Cambrésis, TEMPO - EA \\ 4542, DF2T, Le Mont Houy 59313 \\ Valenciennes Cedex 9, France \\ * Corresponding author: \\ Fethi.Aloui@univ-valenciennes.fr
}

\author{
${ }^{3}$ Mohand TAZEROUT \\ 3 LUNAM Université, École des Mines de \\ Nantes, DSEE, GEPEA CNRS-UMR 6144 \\ 4 rue Alfred Kastler BP207 2244307 \\ Nantes, France \\ E-mail: Mohand.Tazerout@mines-nantes.fr
}

\begin{abstract}
In this work, catalytic cracking of waste fish oil (WFO) to bio-fuel for diesel engine was studied over hybrid catalysts (Sodium carbonate $\mathrm{Na}_{2} \mathrm{CO}_{3}$ /Magnesium oxide). The experiments were conducted using a fix-bed reactor. The effect of catalyst-to-WFO ratio and the amount of each catalyst were studied over the yields of bio-oil and acid value $\mathrm{AV}$, of the bio-oil following central composite design (CCD). The statistical analysis showed that catalyst significantly affected the biooil yield and acid value. A higher bio-oil yield over $70 \mathrm{wt} \%$ with a lower acid value $\left(2.7 \mathrm{mg} \mathrm{KOH} / \mathrm{g}_{\text {oil }}\right)$ were identified at catalyst-to-WFO of 1:7 by using the same amount of sodium carbonate and magnesium oxide. The optimum bio-oil was analyzed and properties have been investigated and compared to diesel fuel physical properties.
\end{abstract}

\section{INTRODUCTION}

The depletion of fossil fuel reserves and a requirement to reduce greenhouse gas emissions have made the discovery and exploitation of new sources of energy [1]. There are many biomasses that have been proposed as bio-resource energy. To produce biofuel, biomass feedstock should have a low price, minimum byproducts and waste and not compete with food industry [2]. Waste biomass such as non-edible oil, recycled cooking greases, agricultural residues, municipal waste, industrial effluents and animal waste includes yellow grease, brown grease, beef tallow, meat and poultry waste, and fish waste are all possible feedstock for deriving biofuels [3, 4]. Biofuels from waste have the advantage of recovering a valuable by-product from a waste stream thus decreasing the volume of waste and toxicity. In recent years, fish consumption 
has been on the rise, such a trend has resulted in the generation of large amounts of fish waste, mostly from industrial processes, which have not been utilized efficiently, as untreated fish waste is customarily disposed of via landfill, incineration, or by dumping into the sea [5]. According to the Food and Agriculture Organization (FAO), in 2005 the estimated world fish production was around 142 MT. Approximately $75 \%$ of this production is used for direct human consumption. The remaining $25 \%$ is destined for non-food products. For 2008, the estimated world fish production was $144 \mathrm{MT}$. The volume of waste produced by processing plants is calculated to be around $50 \%$ of the total processed fish, for which the amount of oil varies from $40 \%$ to $65 \%$ [6]. About 250,000 MT of fish processing waste is produced worldwide and could be converted into biofuel [6]. The Bio-fuel produced can be used as fuel or fuel additive for stationary engines or vehicles. An alternative fuel to petro-diesel must be technically feasible, economically competitive, environmentally acceptable, and easily available.

There are several methods for conversion of biomass into biofuel. These include both biological as well as thermochemical technologies. There are four major methods for thermochemical conversion of organic wastes to synthetic fuels: (1) hydrogenation, (2) pyrolysis, (3) gasification, and (4) bioconversion [7]. Biomass pyrolysis has a long history and considerable future potential, driven by the increased interest in renewable energy. Thermal cracking (pyrolysis) of biomass involves the thermal breakdown at high temperatures in the absence of oxygen [9, 10, 11]. This process is affected by factors such as heating rate, reactor temperature, residence time and composition of the feedstock. Products of biomass pyrolysis include bio-gas, bio-char and bio-oil [12]. Pyrolysis process is thought to have great promise as a means for converting biomass into chemicals and higher value fuels. Bio-oil has a diverse range of potential applications including use as a liquid fuel to fire boilers and furnaces and for combined heat and power using gas turbines or specialist static diesel engines. However, there are major concerns regarding its properties which will need to be upgraded before its utilization becomes possible at scales greater than laboratory testing $[14,15]$. These problems include generally stability, viscosity and corrosivity, which are strongly associated to its chemical composition. Indeed, bio-oil produced is usually mixtures of oxygenated components such as alcohols, ethers, aldehydes, ketones, phenols, esters, and carboxylic acids [13]. Upgrading of the oil stability decrease of acidity and increase of the energy density can be achieved by removal of oxygenates that cause these problems [16]. Upgrading technologies proposed are referring mostly to the molecular distillation, catalytic hydrotreatment, catalytic carking [17, 18] and catalytic esterification of the bio-oil [19].

Numerous studies about catalytic cracking of triglycerides have been developed and researches have shown that this process offers a great potential for future development as a route to improve bio-oil properties [20]. Adding a proper catalyst might change the network of reactions (e.g. deoxygenation) during the pyrolysis process and result in an in-situ upgrading of the bio-oil. A variety of catalysts have been tested to improve bio-oil quality and to increase its yield including molecular sieve catalysts such as ZSM-5, MCM-41 and Y zeolite, activated alumina, transition metal catalysts and sodium carbonate [13, 21, 22, 23]. Xu et al. [20] and Mrad et al. [24] have used a variety of catalyst for triglyceride catalytic cracking and they found that the base catalyst such us $\mathrm{Na}_{2} \mathrm{CO}_{3}$ give pyrolytic oils with low acid value and the product showed good solubility in diesel at low temperature.

The experiments discussed in this paper were designed to optimize the bio-oil yield and acid value for fish wax catalytic cracking using a mixture of $\mathrm{MgO}$ and $\mathrm{Na}_{2} \mathrm{CO}_{3}$ as a hybrid catalyst. This study's main objective was to develop an approach for better understanding the relationships between the catalysts $\left(\mathrm{MgO}\right.$ and $\left.\mathrm{Na}_{2} \mathrm{CO}_{3}\right)$ and the response (product yield and bio-oil acid value) to obtain the optimum conditions for catalytic cracking production using central composite factorial design and response surface methodology (RSM). The effect of temperature was studied too. 


\section{EXPERIMENTAL STUDY}

\subsection{MATERIEL FEEDSTOCK}

The feedstock used in our work is an industry waste obtained from, SIRH group specialized in vegetable, animal and marine oils located in north of France. To produce edible omega 3 fish oil, the fish was treated by a series of processes; starting with cooking it thoroughly in boiling water, pressure it and centrifugation of the product to separate the crude oil and the water and impurities. The crude oil undergone a filtration by winterization to make it limpid by removing the waxes or fats naturally contained. Indeed, the oil was slowly cooled down to obtain a homogeneous crystallization of waxes and fats. It was then filtered through cloths that retain these waxes or fats. The Fat, residue of this treatment, was brown in color and was used in this study without any special purification treatment. The main components of this organic matter are triglycerides, and contain mono and diglycerides, free fatty acids, phospholipids, glycolipids, sterols, and can contain other fat-soluble components including tocopherols, tocotrienols, carotenoids and squalene. The physicochemical properties and the typical fatty acid composition of the WFO have been analyzed and regrouped in Table 1.

Triglyceride pyrolysis products can be catalytically decarboxylated using different kinds of catalysts. The aim of this work is to decarboxylate the pyrolytic vapors to reduce the amount of carboxylic acid of the bio-oil fraction and enhance hydrocarbon formation. For this purpose, two types of catalysts are selected: the magnesium oxide, $\mathrm{MgO}$, purchased from Sigma -Aldrich used in powdered form and sodium carbonate, $\mathrm{Na}_{2} \mathrm{CO}_{3}$, purchased from Panreac Quimica Sa. The hybrid catalysts were prepared by impregnating the magnesium oxide and the sodium carbonate without any previous treatment.

The experiments were conducted by varying the amount of each catalyst to determine its influence on the quality as well as on the quantity of the bio-oil fraction product.
Table1. Main Characteristics of the WFO

\begin{tabular}{ll}
\hline Properties & WFO \\
\hline \hline Visual aspect & $\begin{array}{l}\text { Liquid at } 60^{\circ} \mathrm{C} \text {,brown } \\
\text { color, typical smell }\end{array}$ \\
\hline Water content $(\%)$ & $<0.05 \%$ \\
\hline Flash point $\left({ }^{\circ} \mathrm{C}\right)$ & 318 \\
\hline Acid value $\left(\mathrm{mg}_{\mathrm{KOH}} / \mathrm{g}_{\text {oil }}\right)$ & 2.000 \\
\hline $\mathrm{HHV}(\mathrm{kJ} / \mathrm{kg})$ & 39,000 \\
\hline Kinematic viscosity $\left(\mathrm{mm}^{2} / \mathrm{s}\right)$ & 27 \\
\hline Density $\left(\mathrm{kg} / \mathrm{m}^{3}\right)$ & 0.893 \\
\hline Composition of fatty acids $(\%)$ & \\
\hline Mysteric & 1.050 \\
\hline Palmitoleic & 5.000 \\
\hline Palmitic & 16.00 \\
\hline Stearic & 10.50 \\
\hline Oleic & 45.60 \\
\hline Linoleic & 20.60 \\
\hline
\end{tabular}

\subsection{CATALYTIC CRACKING PROCEDURE}

Catalytic cracking experiments were carried out at temperatures ranging from 350 to $480^{\circ} \mathrm{C}$ with a slow heating rate of $2 \sim 3^{\circ} \mathrm{C} / \mathrm{min}$ using a laboratory scale reactor shown in Figure 1.

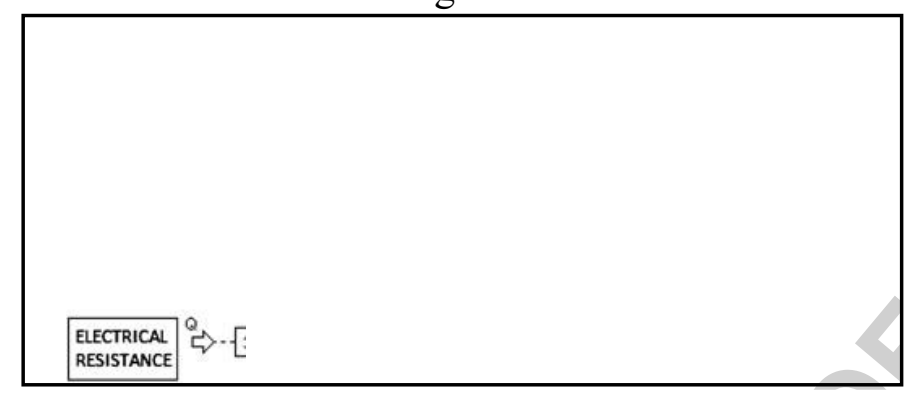

Figure 1. Schematic diagram of catalytic cracking process

The waste was introduced in the reactor and then heated by an external electric resistance. The catalyst is placed just above the fat on a bed with small holes. When the temperature inside the reactor achieved $350^{\circ} \mathrm{C}$, the wax fish was cracking. The generated vapors comes in contact with the surface of catalyst, before leaving through the top of the reactor. After that, they enter in a counter flow, water-cooled, heat ex-changer where water was kept at $15^{\circ} \mathrm{C}$. As a result, two fractions were collected in the flask; the first is the pyrolysis water, and the other represents the bio-oil fraction. The products 
yields $(\mathrm{Yi})$ of this process are given by equations (1), (2) and (3) bellow:

$$
\begin{aligned}
& Y_{b l}(\%)=\frac{\text { wieght of bio-oil }}{\text { weight of } W F R} \times 100 \\
& Y_{c k}(\%)=\frac{\text { wieght of carbon residue }}{\text { weight of } W F R} \times 100 \\
& Y_{g}(\%)=100-Y_{b l}-Y_{c k}
\end{aligned}
$$

where index $c k, g$ and $b l$ denote carbon residue, gas, and bio-oil fraction.

\subsection{EXPERIMENTAL METHODOLOGY}

In order to optimize the yield and the acid value of bio-oil product, a factorial experiment design and response surface methodology were adopted in this study. The $\mathrm{MgO}$ and $\mathrm{Na}_{2} \mathrm{CO}_{3}$ amounts were selected as factors. The experimental design applied in the present study was a Central Composite Design (CCD) for two independent variables at five levels. The total number of experiments was 14: four factorial points, four axial points (start points), and six central points to evaluate the curvature effects defined as the difference between the average of the center point responses and the average of the factorial point responses. The distance of the star points encoded as $+\alpha$ and $-\alpha$ from the center point was $\alpha=2^{n} / 4$, where $n$ is the number of factors $(\alpha=1.414)$. For statistical calculations, the variables $X_{i}$ were coded as $\mathrm{X}_{\mathrm{i}}$ according to the following relationship:

$$
x_{i}=\frac{X_{i}-X_{0}}{\Delta X}
$$

where $X_{0}$ is the average value of variables in high and low levels. $\Delta X$ is the half of the sum of variable at high level-variable and at low level. $x_{1}$ is a coded variable that represents the $\mathrm{MgO}$ amount, $x_{2}$ is a coded variable that represents the $\mathrm{Na}_{2} \mathrm{CO}_{3}$ amount. The range and levels of the variables investigated for the design of the selected factors and the central points are listed in Table 2.

Table 2: Factors and their levels for Central Composite Design

\begin{tabular}{lllllll}
\hline \multirow{2}{*}{ Factors } & \multirow{2}{*}{ Symbol } & \multicolumn{7}{c}{ Range and level } \\
\cline { 3 - 7 } & & -1.414 & -1 & 0 & +1 & +1.414 \\
\hline $\mathrm{MgO}(\% \mathrm{wt})$ & $x_{1}$ & 0.17 & 1 & 3 & 5 & 5.82 \\
$\mathrm{Na}_{2} \mathrm{CO}_{3}(\% \mathrm{wt})$ & $x_{2}$ & 0.17 & 1 & 3 & 5 & 5.82 \\
\hline \hline
\end{tabular}

The statistical method of factorial design of experiments eliminates the systematic errors with an estimate of the experimental error and minimizes the number of experiments. Prior knowledge of the procedure is generally required to produce a statistical model. The three steps used in the experimental design included statistical design of experiments, estimation of coefficients through a mathematical model with response prediction, and analysis of the model's applicability. Since the biooil fraction is the most desired product, thus the optimum operating conditions were determined to maximize its yield $\left(\mathrm{R}_{1}\right)$ and minimize its acid value $\left(\mathrm{R}_{2}\right)$.

\subsection{STATISTICAL ANALYSIS}

Experimental data were analyzed via response surface methodology, in order to fit the following second-order polynomial equation. Second-order coefficients were generated via regression. The response was initially fitted to the factors via multiple regressions. The quality of the fit of the model was evaluated using the coefficients of determination and analysis of variance. The quadratic response surface model was estimated by the following equation:

$$
R_{k}=\beta_{k 0}+\sum_{i=1}^{n} \beta_{k i} x_{i}+\sum_{i=1}^{n} \beta_{k i i} x_{i}^{2}+\sum_{i=1}^{n-1} \sum_{j=i+1}^{n} \beta_{k i j} x_{i} x_{j}
$$

in which $R_{k}$ is the response factor (yield and acid value), $x_{i}$ is the independent factor, $\beta_{0}$ is the intercept, $\beta_{i}$ is the first-order model coefficient, $\beta_{i i}$ is the quadratic coefficient for the factor $i$, and $\beta_{i j}$ is 
the linear model coefficient for the interaction between factors $i$ and $j$.

\subsection{BIO-OIL ANALYSIS}

The key biofuel parameters include acidity, viscosity, density, flash point, oxidation stability, and thermal properties. The acid value is a measure of the amount of carboxylic acid and it was determined by titration with $\mathrm{KOH} / \mathrm{C}_{2} \mathrm{H}_{5} \mathrm{OH}$ solution using phenolphthalein as an indicator. The samples were dissolved in a mixture of ethyl alcohol and diethyl ether (molar report: 1:1) and the acids groups were neutralized with $\mathrm{KOH} / \mathrm{C}_{2} \mathrm{H}_{5} \mathrm{OH}$ solution. Acid number $\left(\mathrm{mg} \mathrm{KOH}_{\mathrm{H}} / \mathrm{g}_{\mathrm{oil}}\right)$ for bio-oil should to be lower than $0.50 \mathrm{mg}_{\mathrm{KOH}} / \mathrm{g}_{\mathrm{Oil}}$ according to both EN 14214 and ASTM D6751 norms of standard fuels. The fuel viscosity an density are an important parameters in the fuel injection process performance. If the viscosity of the fuel is high, then the fuel will not atomize properly resulting in poor engine performance. In our study, kinematic viscosity was calculated by dividing dynamic viscosity by density. To estimate the dynamic viscosity, a SV10 Vibro Viscometer was used. Density was measured with a densimeter having a precision of $0.01 \mathrm{~kg} / \mathrm{l}$. Elemental analyses for carbon, hydrogen, nitrogen and oxygen are routinely determined by the classical total oxidation method (combustion analysis). Elemental composition analysis $(\mathrm{C}, \mathrm{O}$ and $\mathrm{H})$ was determined using a CHNS-O Analyzer (Flash EA 1112, CE Instruments). The heating value was measured using an isoperibolic PARR 6200CLEF calorimeter. In order to identify bio-oil composition a $\mathrm{MS} / \mathrm{CG}$ analysis was carried out. In this purpose a Perkin Elmer TurboMass Gold Mass Spectrometer coupled with a gas chromatograph CLARUS 500 was used. The column was SBLTM-5ms Capillary type, $30 \mathrm{~m}$ in length and $0.25 \mathrm{~mm}$ in internal diameter. The detector temperature was $350{ }^{\circ} \mathrm{C}$ and the injector temperature was $250{ }^{\circ} \mathrm{C}$.

\section{RESULTS AND DISCUSSIONS}

The main purpose of this study is to determine the catalytic activity in thermo-catalytic cracking of the waste fat of fish.
The catalytic activity was measured via products yields and the content of carboxylic acid of the biooil. The experimental matrix and results for this study are shown in Table 3. For each experiment, $\mathrm{CO}_{2}, \mathrm{CO}$ and $\mathrm{H}_{2}$ produced were analyzed too and presented in table 3 . The obtained data enabled us to predict the effectiveness of the catalyst: percentages of $\mathrm{CO}_{2}$ and $\mathrm{CO}$ gave us an idea respectively about decarboxylation and decarbonylation.

Table. 3: bio-oil yields and acid value results

\begin{tabular}{cccccccc}
\hline & & & \multicolumn{5}{c}{ Responses } \\
\cline { 5 - 8 } $\mathrm{N}^{\circ}$ & $x_{1}$ & $x_{2}$ & $R_{1}$ & $R_{2}$ & $\begin{array}{c}C O_{2} \\
(\%)\end{array}$ & $\begin{array}{c}C O \\
(\%)\end{array}$ & $\begin{array}{c}H_{2} \\
(\%)\end{array}$ \\
\hline 1 & -1 & -1 & 62.25 & 9.0 & 12.6 & 6.52 & 11.89 \\
\hline 2 & 1 & -1 & 63.45 & 6.2 & 27.16 & 11.54 & 4.62 \\
\hline 3 & -1 & 1 & 62.00 & 6.0 & 28.69 & 12.67 & 5.26 \\
\hline 4 & 1 & 1 & 72.00 & 2.7 & 22.77 & 9.98 & 7.78 \\
\hline 5 & 0 & 0 & 67.00 & 2.8 & 25.33 & 14.50 & 6.19 \\
\hline 6 & 0 & 0 & 69.00 & 3.0 & 25.56 & 13.50 & 6.00 \\
\hline 7 & 0 & 0 & 70.00 & 2.9 & 26.50 & 14.89 & 7.00 \\
\hline 8 & 0 & 0 & 69.20 & 4.0 & 22.40 & 12.97 & 6.50 \\
\hline 9 & 0 & 0 & 68.50 & 3.2 & 24.60 & 14.70 & 6.23 \\
\hline 10 & 0 & 0 & 71.00 & 3.0 & 24.00 & 14.30 & 6.38 \\
\hline 11 & $-\alpha$ & 0 & 68.00 & 6.0 & 27.78 & 14.94 & 5.88 \\
\hline 12 & $+\alpha$ & 0 & 66.00 & 5.0 & 29.98 & 13.75 & 2.98 \\
\hline 13 & 0 & $-\alpha$ & 65.00 & 6.0 & 26.00 & 12.50 & 3.75 \\
\hline 14 & 0 & $+\alpha$ & 68.50 & 5.0 & 29.28 & 12.70 & 7.52 \\
\hline
\end{tabular}

\subsection{STATISTICAL ANALYSIS}

The obtained responses in all experiments were utilized to develop a quadratic polynomial equation, which correlates the response as a function of parameters. The quadratic polynomial equation allows researchers to find the desired optimum yield and acid value of the bio-oil. The quadratic regression model (based on the coded factors) of the experimental data was given as:

$$
\begin{aligned}
Y_{b l}= & 69.11+1.48 x_{1}+2.34 x_{2}-3.09 x_{1}^{2}-3.34 x_{2}^{2} \\
& +4.4 x_{1} x_{2}
\end{aligned}
$$

$$
\begin{aligned}
A V= & 3.15-1.064 x_{1}-1.114 x_{2}+1.356 x_{1}^{2}+1.35 x_{2}^{2} \\
& +0.125 x_{1} x_{2}
\end{aligned}
$$


The correlation for uncoded levels is described below:

$$
\begin{aligned}
Y_{b l}= & 58.8+2.015 x_{1}+2.88 x_{2}-0.77 x_{1}^{2}-0.83 x_{2}^{2} \\
& +1.1 x_{1} x_{2} \\
A V= & 12.8-2.65 x_{1}-2.35 x_{2}+0.03 x_{1}^{2}+0.03 x_{2}^{2} \\
& +0.33 x_{1} x_{2}
\end{aligned}
$$

The empirical mathematical model was tested with the analysis of variance (ANOVA) using Minitab software which includes the experimental design, data analysis, and quadratic model buildings and graph (figures 2 and 3). The ANOVA was used for checking the significance of the second-order models.

The statistical significance of the second-order model equation was determined by F-value. The determination coefficient gained at $95 \%$ of confidence level for the designed experiments. Responses surfaces were plotted for each response $\left(\mathrm{R}_{1}\right.$ and $\left.\mathrm{R}_{2}\right)$ on the basis of the model equation, to investigate the interaction among the variables and to determine the optimum condition of each factor.
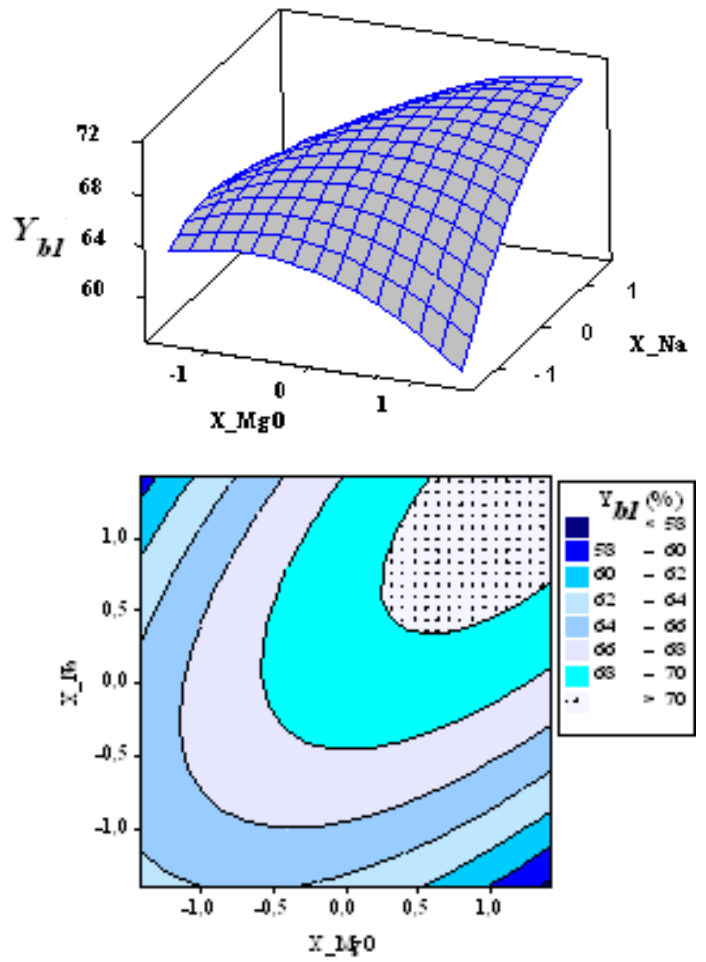

Figure 2. Response surface and contour plot of the effect of catalyst amount on bio-oil yield

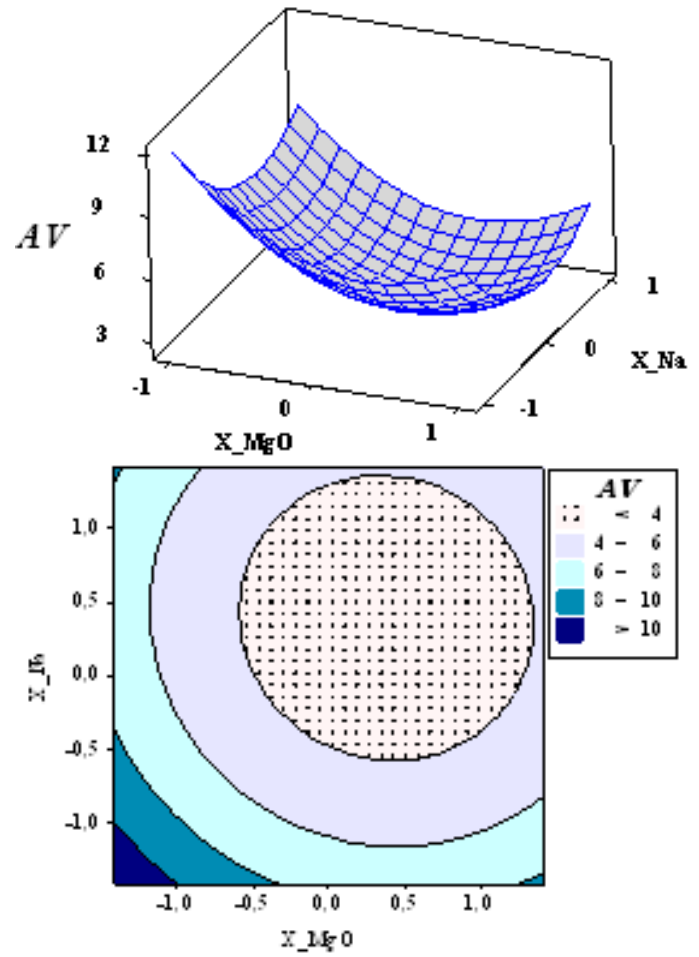

Figure 3. Response surface and contour plot of the effect of catalyst amount on bio-oil acid value

\subsection{OPTIMIZATION PROCESS}

Optimization studies of triglyceride catalytic cracking by employing RSM analysis have been reported by several researchers. In this study, numerical optimization was carried out to find the optimum which resulted in maximum yield of biooil with a minimum acid value. In numerical optimization, the independent parameters which include amount of $\mathrm{MgO}$, and amount of $\mathrm{Na}_{2} \mathrm{CO}_{3}$ were set to 'within the range' between low $(-1)$ and high $(+1)$ while the yield was set to 'maximum' value. Subsequently, the software generated solutions and the solution with the highest desirability was selected and the validity of the optimum results was verified by three independent runs of experiment. The maximum yield of bio-oil was $70 \%$ using respectively $3.7(\% \mathrm{wt})$ of $\mathrm{MgO}$ and $\mathrm{Na}_{2} \mathrm{CO}_{3}$ amount. The experimental error is only $3.3 \%$ which is less than the acceptable range of $\pm 5 \%$. Consequently, it is proven that the developed model is adequate to predict the yield of bio-oil. With the same amount of catalysts, the minimum acid value was obtained $\left(2.7 \mathrm{mg}_{\mathrm{KOH}} / \mathrm{g}_{\mathrm{oil}}\right)$ and the 
comparison of predicted and experimental values was conducted under the same conditions process. Several experiments were carried out at these optimum conditions to verify the accuracy of the proposed model.

\subsection{PRODUCT ANALYSIS}

After optimization, the bio-oil with a low amount of carboxylic acid and represent a highest yield was analyzed and properties have been investigated and compared to diesel fuel specifications according to the ASTM standards. Table 4 gives the results of the bio-oil analysis. The chemical composition of the bio-oil is complex. It contains several chemical species, which are classified into, alcohols, aldehydes, esters, ketones, phenols, alkenes and carboxylic acids.

Table 4. Properties of bio-oil

\begin{tabular}{llcc}
\hline & Unity & Bio-oil & Diesel \\
\hline \hline Density & $\mathrm{Kg} / \mathrm{m}^{3}$ & 822 & 830 \\
\hline $\mathrm{HHV}$ & $(\mathrm{MJ} / \mathrm{Kg})$ & 42 & 43.36 \\
\hline Viscosity & $\left(\mathrm{Ns} / \mathrm{m}^{2}\right)$ & 3 & 2.52 \\
\hline Acid value & $\left(\mathrm{mg}_{\mathrm{KOH}} / \mathrm{g}\right)$ & 2.7 & - \\
\hline Elemental analysis & & \\
\hline$H$ & $(\%)$ & 12 & 13.3 \\
\hline$N$ & $(\%)$ & 0 & 0.2 \\
\hline$O$ & $(\%)$ & 8 & 0.2 \\
\hline$C$ & $(\%)$ & 70 & 86 \\
\hline
\end{tabular}

As seen in Table 4, the properties of produced biodiesel are accordance with biodiesel properties.

\subsection{INFLUENCE OF TEMPERATURE ON THE BIO-OIL COMPOSITION}

Temperature appears to be the key parameter to the synthesis orienting the formation of a specific product. In this portion of the study, we tried to investigate the influence of temperature on the formation of various chemical species on the biooil. We selected to conduct this study, the optimal conditions $3.76 \% \mathrm{MgO}$ and 3.76\% $\mathrm{Na}_{2} \mathrm{CO}_{3}$, for which we have obtained the best results. For this experiment, we recovered the condensed liquid at different temperature ranges; IT1: from room temperature to $380{ }^{\circ} \mathrm{C}$, IT2 from $380^{\circ} \mathrm{C}$ to $400^{\circ} \mathrm{C}$, IT3: from $400{ }^{\circ} \mathrm{C}$ to $430^{\circ} \mathrm{C}$ and IT4: from $430{ }^{\circ} \mathrm{C}$ to the end of the process (figure 4). The results relating to the acid as well as yields of each phase are presented in the table 5 .

Each fraction obtained was analyzed with CG/MS. The identification of the peaks (figure 5) shows the presence of a number of hydrocarbons classes (alkanes, alkenes, oxygenates alcohols, aldehydes, ketones, carboxylic acids).

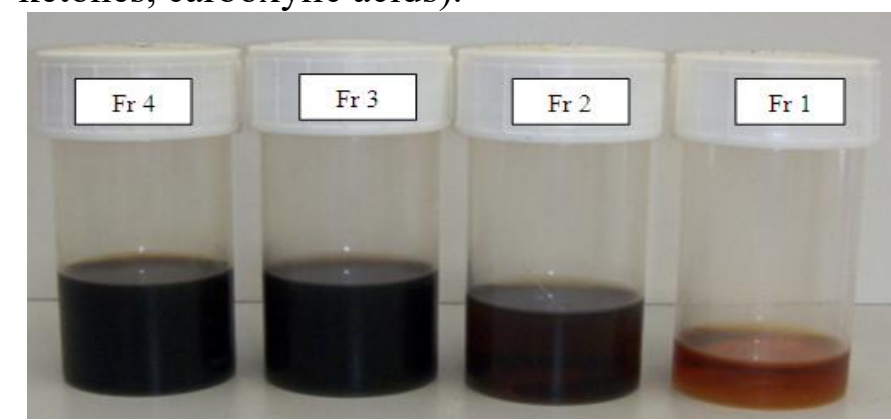

Figure 4. Bio-oil fractions for different temperature ranges

Table 5. Acid value of the fractions recovered

\begin{tabular}{lcc} 
Temperature & Fraction & $\mathrm{AV}\left(\mathrm{mg}_{\mathrm{KOH}} / \mathrm{g}_{\mathrm{oil}}\right)$ \\
\hline \hline IT1 & Fr1 & 11 \\
\hline IT2 & Fr2 & 1.4 \\
\hline IT3 & Fr3 & 0.6 \\
\hline IT4 & Fr4 & 0.36 \\
\hline
\end{tabular}

Analysis retrieved for each temperature range allowed to highlight the evolution of components with the reaction temperature. Indeed, we observed that the process begins at about $380^{\circ} \mathrm{C}$ marked the formation of alkanes $\mathrm{C} 13$ and $\mathrm{C} 15$ as major compounds. We have also noted the absence of heavy compounds (retention time $>18 \mathrm{~min}$ ) and a low presence of those so called volatile. With increasing temperature, we noted:

- Occurrence of couple alkane-alkene with a chain length varying between 9 and 17 carbon atoms,

- Ketones with 15 and 17 carbon atoms begin to form at about $400{ }^{\circ} \mathrm{C}$ and become the major components in the last fraction recovered,

- Occurrence of heavy components when temperature reach $430{ }^{\circ} \mathrm{C}$, 
- Temperature favors the formation of alkenes from the corresponding alkanes, and this can be observed in figure 3 ,

- Presence of carboxylic acids C14: 0 and C16: 0 in the first two fractions. This explains the acidity of these two fractions (11 and 1.4 $\left.\mathrm{mg}_{\mathrm{KOH}} / \mathrm{g}_{\mathrm{oil}}\right)$.
With the increase of temperature, the formations of alkenes are more intense. Indeed, at the end of the process, the heights of peaks corresponding to alkenes becomes more important compared to the corresponding alkanes, and this is observed for hydrocarbons C8 to C14. Gas analysis confirms these trends.
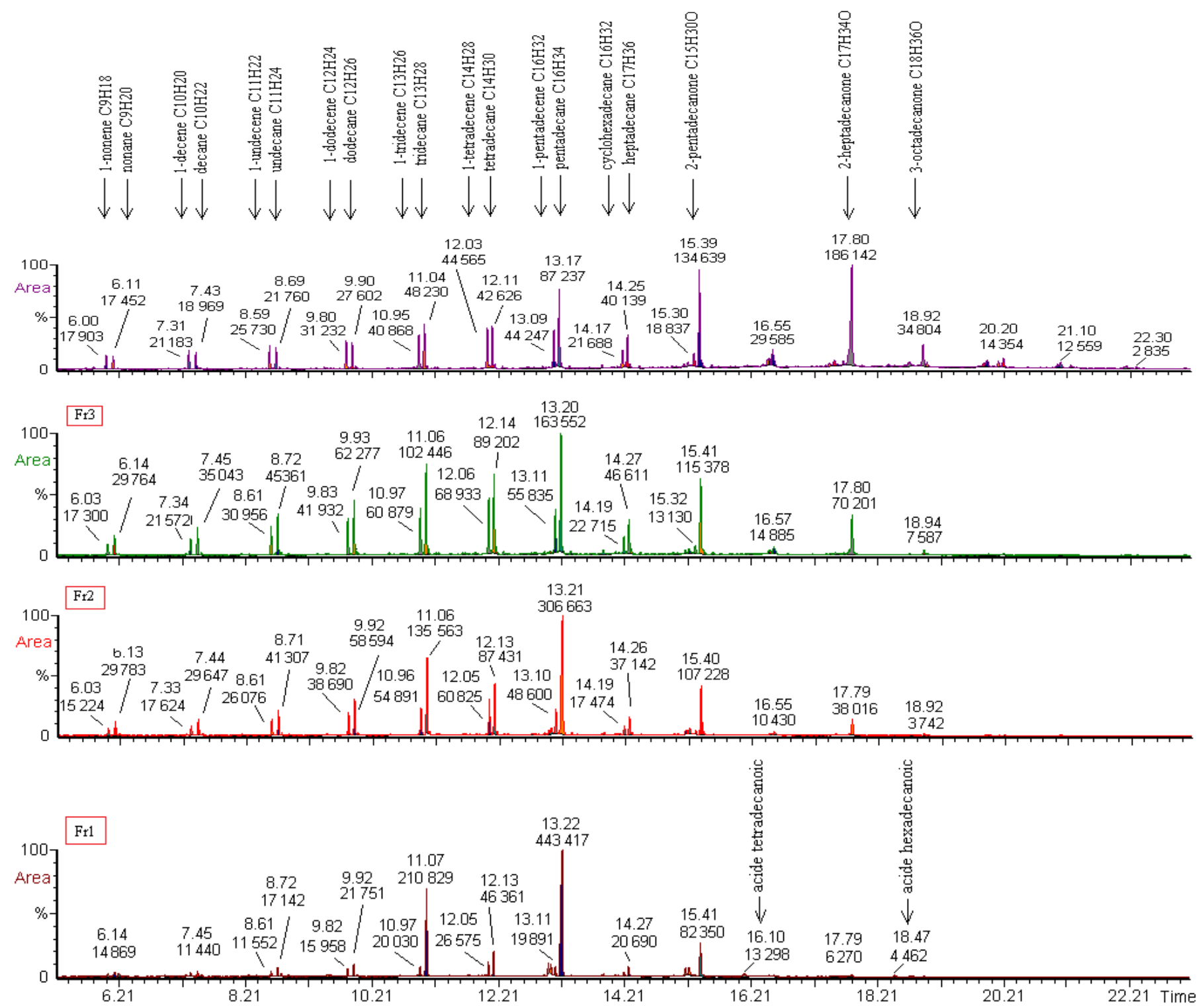

Figure 5. Gas chromatogram of the bio-oil fractions

\section{CONCLUSIONS}

In this study, catalytic cracking was evaluated for catalytic cracking of waste industrial fish fat to produce biofuel. Hybrid catalysts $\left(\mathrm{Na}_{2} \mathrm{CO}_{3} / \mathrm{MgO}\right)$ are used. The effect of catalyst-to- waste ratio and the amount of each catalyst were studied over the yields and acid value of the bio-oil following central composite design. Mathematical model equations were built using sets of experimental data and ANOVA and the optimum 
yield and acid value of bio-oil was $70 \%$ and $2.7 \mathrm{mg}_{\mathrm{KOH}} / \mathrm{g}_{\mathrm{oil}}$ respectively. This result is achieved with a amount of $3.7 \%$ (wt) of each catalyst used. The bio-oil obtained is mainly composed of hydrocarbons, and this chemical composition showed the possibility to produce a useful fuel from waste at high range of temperature. It is concluded that the biofuel production by catalytic cracking of the fish oil industrial waste could be a solution to both ecological and economical aspect because it could contribute to reduce the amount of fat and waste production costs in the industrial sector.

\section{ACKNOWLEDGMENTS}

This research was supported by the GEPEA Laboratory and the Department of Energetic and Environmental Systems (DSEE) at the École des Mines of Nantes. These supports are gratefully acknowledged.

\section{REFERENCES}

[1] Robbinsa Mark P., Geraint Evansb, John Valentinea, Iain S. Donnisona, Gordon G. Allisona, New opportunities for the exploitation of energy crops by thermochemical conversion in Northern Europe and the UK- Review. Progress in Energy and Combustion Science; 38: 138-155, 2012.

[2] Babich I.V., van der Hulst M., Lefferts L., Moulijn J.A., O'Connor P., Seshan K., Catalytic pyrolysis of microalgae to highquality liquid bio-fuels. Biomass and bioenergy, 35: 3199-3207, 2011.

[3] Balat M., Global trends on the processing of biofuels. Int J. Green Energy, 5:212-38, 2008.

[4] Balat M., Demirbas M.F., Recent advances on the production and utilization trends of biofuels: a global perspective. Energy Convers. Manage, 47:2371-81, 2006.

[5] Van Thingoc Dao, Joong KyunKim, Scaled-up bioconversion of fish waste to liquid fertilizer using a $5 \mathrm{~L}$ ribbon-type reactor. Journal of Environnemental Management, 92: 2441-2446, 2011.

[6] Yahyaee R., Ghobadian B., Najafi G., Waste fish oil biodiesel as a source of renewable fuel in Iran. Renewable and Sustainable Energy Reviews, 17: 312-319, 2013.

[7] Demirbas M. F., Balat M., Balat H., Biowastes-to-biofuels. Energy Conversion and Management, 52: 1815-1828, 2011.
[8] Vamvuka D., Bio-oil, solid and gaseous biofuels from biomass pyrolysis processes - An overview. International Journal of Energy Research, 35:835-862, 2011.

[9] Prasad R., Srivastava A., Triglycerides-based diesel fuels. Renew Sustain Energy Rev., 4:111-33, 1999.

[10] Hanna M.A., Ma F., Biodiesel production: a review. Bioresource Technol., 70:1-15, 1999.

[11] Goyal H.B., Saxena R.C., Seal D., Bio-fuels from thermochemical conversion of renewable resources: a review. Renew Sustain Energy Rev., 2:504-17, 2008.

[12] Demirbas A., Pehlivan E., Altun T., Potential evolution of Turkish agricultural residues as bio-gas, bio-char and bio-oil sources. Int. J. Hydrogen Energy, 31:613-20, 2006.

[13] Maher K.D., Bressler D.C., Pyrolysis of triglyceride materials for the production of renewable fuels and chemicals. Bioresource Technol., 98:2351-68, 2007.

[14] Bridgwate A.V., Principles and practice of biomass fast pyrolysis processes for liquids. Journal of Analytical and Applied Pyrolysis, 51:3-22, 1999.

[15] Huber G.W., Iborra S., Corma A., Synthesis of transportation fuels from biomass: chemistry. Catalysts and Engineering Chemical Reviews, 106: 4044- 4048, 2006.

[16] Kersten S.R.A., van Swaaij W.P., Lefferts L., Seshan K., Options forCatalysis in the thermochemical conversion of biomass intofuels. In: Centi G., van Santen R.A., Editors. Catalysis for renewables. Germany: Willey-VCH, p. 119-62, 2007.

[17] Zhu X.F., Venderbosch R.H., Experimental research on gasification of bio-oil derived from biomass pyrolysis. Journal of Fuel Chemistry and Technology, 32: 510-512, 2004.

[18] Pramila T., Subhash B., Catalytic cracking of palm oil for the production of biofuels: Optimization studies. Bioresource Technology., 98: 3593-3601, 2007.

[19] Mahfud F.H., eli n-Cabrera I., Manurung R., Heeres H.J., Biomass to fuels upgrading of flash pyrolysis oil by reactive distillation using a high boiling alcohol and acid catalysts. Trans. IChemE, Part B, Process Safety and Environmental Protection, 85: 466-472, 2007.

[20] Xu J., Jiang J., Sun Y., Chen J., Production of hydrocarbon fuels from pyrolysis of soybean oils using a basic catalyst. Bioresource Technology, 101: 9803-9806, 2010.

[21] Dandik, L., Aksoy, H.A. Pyrolysis of used sunflower oil in the presence of sodium carbonate by using fractionating pyrolysis reactor. Fuel Process. Technol., 57: 81-92, 1998.

[22] Konwer D., Taylor S.E., Gordon B.E., Otvos J.W., Calvin M., Liquid fuels from Mesuaferrea L. seed oil. JAOCS, 66:223-226, 1989.

[23] Zaher F.A., Taman A.R., Thermally decomposed cottonseed oil as a diesel-engine fuel. Energy Sources, 15: 499-504,1993.

[24] Mrad N., Paraschiv M., Aloui F, Varuvel E.G., Tazerout M., Ben Nasrallah S., Liquid hydrocarbon fuels from fish oil industrial residues by catalytic cracking. International Journal of Energy Research, DOI: 10.1002/er.2906, 2013. 